oxyd noch Wismuthoxyd reducirte, sich mit Natronlauge erhitzt nicht bräunte, nach Neutralisation und Abdampfen auf kleines Volumen Fällen mit Alkohol einen Niederschlag lieferte, der in Wasser, auch in Kalkwasser unlöslich war, in Essigsäure sich dagegen leicht löste. Es ergiebt sich also aus diesem Verhalten, dass das Mucin bei Anwesenheit von Serumalbumin durch künstlichen Magensaft zwar nicht gespalten wird wie durch verdünnte Säure auf dem Wasserbade, aber doch eine wesentliche Aenderung erfährt, welche es ohne Anwesenheit von Serumalbumin nicht erleidet.

Nach allen diesen geschilderten Reactionèn des Paralbumin aus Ovarialcysten und des Mucin aus Submaxillardrüse scheint es höchst wahrscheinlich, dass das sogenannte Paralbumin Gemenge darstellt von Eiweissstoffen (und zwar, nach der Fällbarkeit durch Spuren von Essigsäure, Lösung in Chlornatriumlösung zu schliessen, hauptsächlich von Globulinstoffen) mit Mucin. Nicht allein alle Reactionen, auch die zuerst von Scherer angegebenen, sprechen für diese Ansicht, sondern ebenso die Analysen von Haerli ${ }^{1}$ ), nach denen die Zusammensetzung im wesentlichen in der Mitte steht zwischen den Eiweissstoffen und dem Mucin.

\title{
Ueber das Schleimgewebe des Nabelstrangs.
}

Von Dr. S. Obolenøky aus St. Petersburg.

In wie weit dem Schleimgewebe Virchows wirklich nachweisbarer Mucingehalt zukommt, ist noch nicht hinreichend festgestellt. Wenn man von menschlichen Nabelsträngen Arterien und Venen herauspräparirt, das Gewebe zerkleinert und mit kaltem Wasser extrahirt, wird eine Lösung erhalten, welche mit Essigsäure behandelt einen Niederschlag giebt, der sich aber in überschüssiger Essigsäure wieder löst. Fällt man den wässrigen Auszug mit Alkohol und erhitzt den ausgepressten Niederschlag einige Zeit in verdünnter Schwefelsäure auf dem siedenden Wasserbade, so erhält man denselben nicht gährungsfähigen, aber Kupferoxyd oder Wismuthoxyd reducirenden Körper, welcher bei dergleichen Behandlung auch aus

1) A. a. 0 . 
Mucin erhalten wird; es ist somit höchst wahrscheinlich, dass ebenso wie in den Ovarialcystenflüssigkeiten auch im Kaltwasserauszuge des Schleimgewebes der Mucingehalt wegen der zugleich ausgezogenen Eiweissstoffe nicht direct durch Essigsäure nachgewiesen werden kann, derselbe aber das Auftreten des reducirenden zuckerähnlichen Körpers bei der Behandlung mit verdünnter Schwefelsäure bedingt. Allerdings können verschiedene Mucinstoffe existiren, welehe bei der Behandlung mit Säuren diese reducirende Substanz geben; es wird jedoch zweckmässig sein, sie vorläufig dem Mucin $\mathrm{zu}$ subsumiren, bis eine bessere Isolirung ermöglicht sein wird.

\section{Ueber den Einfluss des Nervensystems auf den Kreislauf und die Körpertemperatur. \\ Von Dr. Franz Riegel, \\ I. Assistent an der medic. Klinik zu Würzburg.}

\section{Ueber die sogenannten rythmischen Gefässcontractionen.}

Schiff ${ }^{1)}$ hat im Jahre 1854 unter dem Titel "Ein accessorisches Arterienherz bei Kaninchen " eine jetzt allgemein gekannte, wenn auch noch in verschiedener Weise gedeutete Erscheinung am Kaninchenohr beschrieben. An den grösseren Arterien des Kaninchenohrs lassen sich ganz deutliche abwechselnde Verengerungen und Erweiterungen der Gefässe beobachten, wobei der contrahirte Zustand in der Regel länger andauert, als der Zustand der Expansion. Diese Bewegungen erfolgen in der Regel 3-5 Mal in der Minute und hängen, wie Schiff sogleich bemerkte, nicht von der Contraction des Herzens ab, auch nicht etwa von einem starken Druck bei der Exspiration, auch nicht von einem durch Contraction der Muskeln auf die Gefässe ausgeübten Druck. Die Erweiterung tritt sehr häufig ungleichzeitig auf beiden Ohren ein, so dass sie oft auf der einen Seite erst beginnt, wenn sie auf der andern Seite ihre Acne bereits erreicht hat. Schiff hat zu jener Zeit bereits die Abhängigkeit dieser Bewegungen vom Nervensystem in richtiger Weise hervorgehoben, insbesondere den Einfluss der Sympathicus-

1) Archiv für physiologische Heilkunde von Vierordt, 1854. p. 523. 